\title{
cDNA cloning and expression of erythropoietin in the plateau zokor (Myospalax baileyi) from the Qinghai-Tibet Plateau
}

\author{
WANG ZhenLong $^{1,2 \dagger}$, CHEN Yan ${ }^{3,4 \dagger}$, YANG Jie $^{5}$, CHEN WeiJun ${ }^{3 *}$, ZHANG YanMing $^{2 *} \&$ \\ ZHAO XinQuan ${ }^{2 *}$ \\ ${ }^{1}$ Department of Bioengineering, Zhengzhou University, Zhengzhou 450001, China; \\ ${ }^{2}$ Key Laboratory of Adaptation and Evolution of Plateau Biota, Northwest Plateau Institute of Biology, Chinese Academy of Sciences, Xining \\ 810001, China \\ ${ }^{3}$ Beijing Institute of Genomics, Chinese Academy of Sciences, Beijing 100029, China; \\ ${ }^{4}$ Graduate University of the Chinese Academy of Sciences, Beijing 100049, China; \\ ${ }^{5}$ Department of Epidemiology and Statistics, School of Public Health, Hebei Medical University, Shijiazhuang 050017, China
}

Received August 15, 2011; accepted September 23, 2011

\begin{abstract}
All organisms respond to variation in their environments and manage environmental stress through metabolic adjustments. The plateau zokor (Myospalax baileyi) is an endemic and keystone subterranean rodent species that inhabits the Qinghai-Tibet Plateau between 2800 and $4200 \mathrm{~m}$ above sea level. It is a hypoxic-tolerant mammal with a high ratio of oxygen utilization that enables it to cope with its harsh surroundings. To explore the molecular mechanism of altitude acclimatization of the plateau zokor, we cloned the zokor erythropoietin (Epo) gene and used real-time PCR to compare Epo mRNA levels in zokors inhabiting 16 different altitudes. The full-length zokor Epo open reading frame was 579 bp that encoded a precursor peptide of 192 amino acids with a signal peptide of 26 residues. The Epo gene of the plateau zokor was $81 \%-95 \%$ homologous to that of human, mouse, rat, root vole and the Golan Heights blind mole rat, with the highest homology (95\%) to species of the genus Spalax. Epo mRNA was detected mainly in the zokor kidney and spleen among 8 selected tissues. The level of Epo mRNA increased in the liver and kidney with increases in altitude. The increase in the kidney was 5 times that in the liver. Remarkably, expression of Epo mRNA in the kidney of zokors living at the highest altitude $(4268 \mathrm{~m})$ was 12 -fold higher than that of zokors living at the lowest $(2492 \mathrm{~m})$ altitude. These findings provide essential information for understanding the possible role of Epo in adaptation to hypoxia in the plateau zokor.
\end{abstract}

erythropoietin, plateau zokor, cDNA cloning, mRNA expression, altitude

Citation: Wang Z L, Chen Y, Yang J, et al. cDNA cloning and expression of erythropoietin in the plateau zokor (Myospalax baileyi) from the Qinghai-Tibet Plateau. Chin Sci Bull, 2012, 57: 997-1006, doi: 10.1007/s11434-011-4911-3

All organisms have to deal with environmental stress through metabolic adjustment and ultimately they have to adapt to their environment [1]. The Qinghai-Tibet Plateau has an average altitude of $3000 \mathrm{~m}$, making it the highest plateau on earth [2]. Strong ultraviolet radiation, hypoxia and cold are typical of plateaus and have a profound effect on animal survival. Over evolutionary time many animals have developed unique mechanisms in response to these harsh environmental conditions to ensure optimal growth and reproduction [3].

The plateau zokor (Myospalax baileyi) is an important subterranean rodent endemic to the Qinghai-Tibet Plateau. It is tolerant of hypoxia and shows a remarkably high oxygen utilization ratio to cope with the plateau environment, making it a good model for research into adaptation to hypoxia [4]. In their sealed hypoxic-hypercapnic burrow, Zo-

$\dagger$ These authors contributed equally to this work

*Corresponding authors (email: chenwj@genomics.org.cn; zhangym@nwipb.ac.cn; zhaoxq@nwipb.ac.cn) 
kors spend their entire life underground, exposed to fluctuating $\mathrm{O}_{2}$ and $\mathrm{CO}_{2}$ levels [5,6]. They are active throughout the year, excavating burrow systems and storing food. As is common in subterranean rodents, the plateau zokor exhibits morphological, physiological and behavioral adaptations to digging and living underground [7]. For example, the zokor has evolved physiological changes to its respiratory and cardiovascular systems to cope with hypoxia [8-10]. The zokor is dramatically superior to Rattus species in microvessel density of cardiac muscle and myocardial performance, and harbors a much higher capillary and mitochondrial density [8]. The zokor has a higher erythrocyte count, an increased lung diffusion capacity, and utilizes a myoglobin that is different in structure to that of Rattus [10]. Moreover, the number of red blood cells, the density of hemoglobin in the red blood cells and the myoglobin content in heart and skeletal muscle are much higher than in other high-altitude mammals inhabiting a plateau environment [11].

Erythropoietin (Epo) is a hematopoietic cytokine that regulates red blood cell production [12]. Epo has 166 amino acid residues and a molecular weight of $18.4 \mathrm{kD}$; however, the overall molecular weight of Epo is $30.4 \mathrm{kD}$ because of three $\mathrm{N}$-linked carbohydrate chains. Two internal disulphide bonds between cysteine residues 7-161 and 29-33 are known to be necessary for biological activity [13]. Epo is expressed mainly in fetal liver and adult kidney $[14,15]$. The regulation of Epo gene expression occurs mainly at the transcriptional level by DNA-dependent mRNA synthesis [16-18] and is controlled by an oxygen detection system that responds to changes in venous rather than arterial partial pressure of oxygen $\left(\mathrm{PO}_{2}\right)$ [19,20]. Clearance of Epo appears to be possible via three routes: excretion through the kidney [21], metabolism by the liver [22] or consumption by the erythron [23]. Epo is essential for the development of normal erythropoiesis, and underproduction of Epo results in anemia [16]. Regulation of erythropoiesis and red blood cell mass relies on modulating Epo gene expression in response to tissue oxygen tension. Developmental, tissue-specific, and environmental signals all contribute to the precise regulation of the Epo gene. Research on ontogenetic expression of the Epo gene and of hypoxic stress tolerance in the subterranean blind mole rat of the Spalaxeh renbergi superspecies has shown that higher Epo mRNA levels exist in the Spalax fetal liver and kidney compared with Rattus. In addition, adult Rattus kidney and liver, and adult Spalax liver express similar levels of Epo mRNA under normoxia and hypoxia [24]. In normoxia, both Spalax and Rattus kidneys produce small amounts of Epo. Notably, under hypoxic conditions, Epo expression in the adult Spalax hypoxic kidney, the major site of erythropoietin production in adult mammals, was remarkably higher than in that of Rattus. Therefore, it can be assumed that Epo is a key factor in coping with underground hypoxic stress and that Epo contributes to the adaptive strategy of hypoxia tolerance [25].
Epo has been cloned from many mammals, including human, monkey, rat, sheep, dog and pig and it shows a high degree of homology among mammals [18,25-27]. However, there have been few reports concerning the Epo gene from species living in high altitude, hypoxic environments. The plateau zokor is a hypoxic-tolerant mammal with a high ratio of oxygen utilization. In this study, the Epo gene of the plateau zokor was cloned, and the predicted amino acid sequences were compared with those of other animals. Further, using real-time PCR, we investigated expression levels of Epo mRNA from 8 tissues and across 16 different altitudes to explore the significance of Epo in the adaptation of the plateau zokor to the harsh environment of the Qinghai-Tibet Plateau.

\section{Materials and methods}

\subsection{Experimental sites and animal sampling}

All procedures involved in the trapping and handling of animals were approved by the Chinese Zoological Society and were conducted in accordance with the Chinese Practice for the Care and Use of Laboratory Animals. Eighty-eight adult zokors (58 females and 30 males) were captured from 16 locations in the eastern region of the Qinghai-Tibet Plateau over two field excursions from April to June in 2006 and 2007. We collected animals from sites dominated by alpine meadows, alpine shrub and farmland where the main differences were altitude (ranging from 2492 to $4268 \mathrm{~m}$ ) and ambient temperature (ranging from -1.3 to $11.8^{\circ} \mathrm{C}$ ). At each location we measured elevation, latitude and longitude using a handhold GPS (eXplorist210, Magellan Corp, USA) (Table 1). Live-trapping was conducted between 09:00 and 16:00 h from April to June. Captured animals were firstly recorded for body weight $(\mathrm{g})$ and body length $(\mathrm{mm})$, then anesthetized using chloral hydrate $(5 \%)$ and killed by cervical dislocation. Dissections were conducted at the trap site. Eight tissue samples (brain, heart, lung, liver, spleen, kidney, muscle and white adipose tissue) were immediately frozen in liquid nitrogen.

\subsection{Preparation of total RNA and cDNA synthesis}

Total RNA was extracted from a 100-mg portion of frozen tissue using TRIZOL reagent (Invitrogen, Carlsbad, USA), and then diluted in $100 \mu \mathrm{L}$ RNase-free water and analyzed by agarose gel electrophoresis. Sharp bands of $18 \mathrm{~S}$ and $28 \mathrm{~S}$ rRNA were used as indicators of high quality preparations. RNA concentration was determined by spectrophotometry using a NanoDrop ND-1000 Spectrophotometer (NanoDrop Technologies, Rockland, USA). RNA samples were treated with RNase-free DNase I (TaKaRa, Dalian, China), then stored at $-80^{\circ} \mathrm{C}$.

Five micrograms of total RNA were used for first-strand cDNA synthesis using a SuperScript ${ }^{\mathrm{TM}}$ II RT Kit (Invitrogen) 
Table 1 Geographic and climate data for 88 samples of Myospalax baileyi from 16 sampling locations across the Qinghai-Tibetan Plateau

\begin{tabular}{|c|c|c|c|c|c|c|c|c|}
\hline \multirow{2}{*}{ No. } & \multicolumn{3}{|c|}{ Populations } & \multicolumn{5}{|c|}{ Ecogeographical variables } \\
\hline & Location & Lat & Long & $N$ & $\mathrm{Al}$ & $T \mathrm{~m}$ & $R \mathrm{n}$ & $V g$ \\
\hline 1 & Gushan, Minhe & $36^{\circ} 07.263^{\prime}$ & $102^{\circ} 43.019^{\prime}$ & 8 & 2492 & 8 & 500 & $\mathrm{Ar}+\mathrm{M}$ \\
\hline 2 & Guojia Mont, Minhe & $36^{\circ} 05.794^{\prime}$ & $102^{\circ} 43.849^{\prime}$ & 6 & 2538 & 8 & 500 & $\mathrm{Fl}+\mathrm{M}$ \\
\hline 3 & Dongxia, Datong & $37^{\circ} 02.731^{\prime}$ & $101^{\circ} 48.310^{\prime}$ & 9 & 2745 & 1.3 & 589.6 & $\mathrm{Fl}+\mathrm{Ar}$ \\
\hline 4 & Xianghua, Datong & $37^{\circ} 06.849^{\prime}$ & $101^{\circ} 47.773^{\prime}$ & 5 & 2889 & 1.3 & 589.6 & $\mathrm{Fl}+\mathrm{M}$ \\
\hline 5 & Hualong & $36^{\circ} 05.023^{\prime}$ & $102^{\circ} 14.003^{\prime}$ & 8 & 2996 & 2.2 & 470 & $\mathrm{Fl}+\mathrm{M}$ \\
\hline 6 & Ditan, Hualong & $36^{\circ} 11.175^{\prime}$ & $102^{\circ} 17.319^{\prime}$ & 8 & 3153 & 2.2 & 470 & $\mathrm{Fl}$ \\
\hline 7 & Xianghua, Datong & $37^{\circ} 11.521^{\prime}$ & $101^{\circ} 45.914^{\prime}$ & 8 & 3215 & 1.3 & 589.6 & $\mathrm{Sh}+\mathrm{M}$ \\
\hline 8 & Sairlong, Henan & $34^{\circ} 31.089^{\prime}$ & $102^{\circ} 01.236^{\prime}$ & 4 & 3386 & 11.9 & 606.3 & St \\
\hline 9 & Banma & $32^{\circ} 51.257^{\prime}$ & $100^{\circ} 49.330^{\prime}$ & 1 & 3464 & 4.2 & 638.4 & $\mathrm{Sh}+\mathrm{M}$ \\
\hline 10 & Aba, Sichuan & $33^{\circ} 27.179^{\prime}$ & $101^{\circ} 55.255^{\prime}$ & 5 & 3474 & 3.3 & 712 & M \\
\hline 11 & Henan & $34^{\circ} 43.293^{\prime}$ & $101^{\circ} 40.946^{\prime}$ & 7 & 3591 & 11.9 & 606.3 & $\mathrm{Sh}+\mathrm{M}$ \\
\hline 12 & Guinan & $35^{\circ} 16.543^{\prime}$ & $101^{\circ} 19.789^{\prime}$ & 1 & 3641 & 2.1 & 398 & M \\
\hline 13 & Manzhang, Dari & $30^{\circ} 16.449^{\prime}$ & $100^{\circ} 27.235^{\prime}$ & 5 & 3963 & -1.3 & 552.4 & M \\
\hline 14 & Manzhang, Dari & $30^{\circ} 16.796^{\prime}$ & $100^{\circ} 27.056^{\prime}$ & 4 & 3977 & -1.3 & 552.4 & M \\
\hline 15 & De'ang, Dari & $33^{\circ} 23.158^{\prime}$ & $100^{\circ} 12.578^{\prime}$ & 4 & 4256 & -1.3 & 552.4 & M \\
\hline 16 & Jiuzhi & $33^{\circ} 18.175^{\prime}$ & $100^{\circ} 52.467^{\prime}$ & 5 & 4268 & 0.1 & 764.6 & M \\
\hline
\end{tabular}

a) Variables are as follows: $N$, number of animals; $\mathrm{Al}$, altitude (in $\mathrm{m})$; Lat, latitude $(\mathrm{N})$; Long, longitude $(\mathrm{E}) ; \mathrm{Tm}, \mathrm{mean}$ annual temperature $\left({ }^{\circ} \mathrm{C}\right) ; R \mathrm{n}$, mean annual rainfall (in mm). Climatic data were obtained from local weather bureaux; Vg, vegetation form: M, meadow; Sh, shrub; St, steppe; Fl, farmland; Ar, arbor.

in a $30-\mu \mathrm{L}$ volume containing $5 \times$ first-strand Buffer, Oligo(dT) ${ }_{18}(20 \mu \mathrm{g} / \mathrm{mL}), 10 \mathrm{mmol} / \mathrm{L}$ dNTPs, $0.1 \mathrm{mmol} / \mathrm{L}$ DTT, RNaseOUT (40 units $/ \mu \mathrm{L}$ ) and reverse transcriptase (40 units $/ \mu \mathrm{L})$. The reaction was carried out at $65^{\circ} \mathrm{C}$ for $5 \mathrm{~min}$, then at $42^{\circ} \mathrm{C}$ for $50 \mathrm{~min}$. The reverse transcriptase was then inactivated at $70^{\circ} \mathrm{C}$ for $15 \mathrm{~min}$. Aliquots of undiluted cDNA were used for PCR and real-time PCR.

\subsection{Cloning the plateau zokor erythropoietin gene}

To obtain a complete open reading frame (ORF) of the plateau zokor Epo gene, forward (Epof 20-39: GAGATGGGGGTGCCCGAACG, accession no. NM_017001) and reverse (Epor 583-602: GTCACCTGTCCCCTCTCCTG) primers were designed with Primer Premier (version 5.0, Premier Biosoft International, Palo Alto, USA) according to the alignment of highly conserved coding sequence regions of the Epo gene among humans (accession no. NM_ 000799), mice (accession no. NM_007942), rats (accession no. NM_017001) and Spalax sp. (accession nos. AJ715792, AJ715793, AJ715794, AJ715795). Total kidney RNA was isolated from 6 zokors, and Epo cDNA was obtained by RT-PCR. The Epo gene product was amplified by PCR using LA Taq DNA polymerase (TaKaRa) in a mixture of 200 $\mu \mathrm{mol} / \mathrm{L}$ dNTP, $0.3 \mu \mathrm{mol} / \mathrm{L}$ primers (Beijing Genomics Institute, Beijing, China) and $2 \times \mathrm{GC}$ Buffer I $\left(\mathrm{Mg}^{2+}\right.$ plus $)$ with $5 \mu \mathrm{g}$ undiluted cDNA template. The PCR reactions were started with $10 \mathrm{~min}$ at $95^{\circ} \mathrm{C}$ followed by 35 cycles consisting of $45 \mathrm{~s}$ at $94^{\circ} \mathrm{C}, 30 \mathrm{~s}$ at $55^{\circ} \mathrm{C}$, and $60 \mathrm{~s}$ at $72^{\circ} \mathrm{C}$. The PCR product of expected size was purified using Axyprep
DNA Gel Extraction Kit (Axygen Biosciences, California, USA) and ligated into pMD19-T (TaKaRa). Five clones from each animal were then sequenced and the full-length Epo cDNA was determined by alignment with the above species. The entire sequence was submitted to the GenBank database (accession no. EU183314).

\subsection{Sequence analysis}

Translation of cDNA nucleotide sequence was performed using the EditSeq program of DNASTAR (DNASTAR, Madison, USA). The nucleotide and deduced amino sequences were compared with sequences in the GenBank database using the BLAST program available from the National Center for Biotechnology Information (NCBI, US National Institute of Health). The signal peptide in the deduced amino acid sequence was predicted with SignalP available from Centre for Biological Sequence Analysis, Technical University of Denmark. Multiple alignments were performed using CLUSTALX (version 1.81, PlateForme de Bio-Informatique, Illkirch, France). Functional motifs were predicted in the deduced amino acid sequence using MotifScan in the PROSITE database of protein families and domains (available from http://myhits.isb-sib.ch/ cgi-bin/motif_scan).

\subsection{Primers and real-time PCR}

The endogenous $\beta$-actin gene was used as the reference gene. Real-time PCR primers for the Epo and $\beta$-actin genes 
were designed using Primer Express Software (v3.0, Applied Biosystems, Carlsbad, USA). For the Epo gene, forward (F: 5'-ACAATGGAGGTGGAAGAACAGG-3') and reverse (R: 5'-ATGGTTGGGAGGAATTGGCT-3') primers amplified a 106-bp fragment. For the $\beta$-actin gene, forward (F: 5'-CTAAGGCCAACCGTGAAAAGAT-3') and reverse (R: 5'-GACCAGAGGCATACAGGGACA-3') primers amplified a 105-bp fragment. Real-time PCR was carried out in $30 \mu \mathrm{L}$, containing $5 \times$ Real Time PCR buffer, $250 \mathrm{mmol} / \mathrm{L}$ $\mathrm{Mg}^{2+}, 10 \mathrm{mmol} / \mathrm{L}$ dNTPs, $10 \mathrm{pmol}$ of each primer, 1:20 SYBR GreenI, $1 \mathrm{U}$ Ex Taq (TaKaRa) and $2 \mu \mathrm{L}$ of cDNA or 10 fold-diluted plasmids on an ABI 7300 instrument (Applied Biosystems). Each sample was tested in triplicate, using the following conditions: initial denaturation for 10 min at $95^{\circ} \mathrm{C}$ followed by 40 cycles of $20 \mathrm{~s}$ at $95^{\circ} \mathrm{C}, 30 \mathrm{~s}$ at $60^{\circ} \mathrm{C}$ and $30 \mathrm{~s}$ at $72^{\circ} \mathrm{C}$. The fluorescence signals were read and collected at the end of each extension step at $72^{\circ} \mathrm{C}$. After amplification, a melting curve analysis with a temperature gradient of $15 \mathrm{~s}$ at $95^{\circ} \mathrm{C}, 30 \mathrm{~s}$ at $60^{\circ} \mathrm{C}$ and $15 \mathrm{~s}$ at $95^{\circ} \mathrm{C}$ was performed to confirm that only the specific products were amplified.

\subsection{Efficiencies of real-time RT-PCR}

The quantities of zokor Epo mRNA were normalized with $\beta$-actin mRNA to compensate for variations in input RNA amounts. To obtain reliable results for the comparative $C_{\mathrm{T}}$ method, efficiencies of amplification of housekeeping and target genes have to be similar. The efficiency has been calculated for each PCR by the following equation, where $S$ is the slope of the standard curve:

$$
\text { Efficiency }(E)=\left[10^{(1 / \text { lope })}\right]-1 \text {. }
$$

By analysis of serial 10-fold diluted plasmids, standard curve equations and linear regression coefficients were calculated automatically by the Real-Time PCR Detection SDS System. Here, efficiency $(E)$ was typically $>0.90$ (Slope $=$ $3.31 \pm 0.20, R^{2}=0.94 \pm 0.02$ ), indicating that PCR amplification of Epo and $\beta$-actin were approximately equal and that the $\Delta \Delta C_{\mathrm{T}}$ method was appropriate.

\subsection{Data analysis}

Using the $2^{-\Delta \Delta C_{\mathrm{T}}}$ method [28], normalization was achieved by dividing the average value of Epo by the average value of $\beta$-actin in each sample. To compare levels between tissues, we used brain as the calibrator sample. Similarly, the expression of Epo in the liver and kidney at different altitudes was compared with the average $\Delta C_{\mathrm{T}}$ value for the altitude $2492 \mathrm{~m} .2^{-\Delta \Delta C_{\mathrm{T}}}$ values larger than 1 indicated a higher expression level.

$$
\begin{gathered}
\Delta C_{\mathrm{T}}=C_{\mathrm{T}(E p o)}-C_{\mathrm{T}(\beta \text {-actin }),} \\
\Delta \Delta C_{\mathrm{T}}=\Delta C_{\mathrm{T}(\text { sample })}-\Delta C_{\mathrm{T} \text { (calibrator) })}
\end{gathered}
$$

Data were analyzed with the program SPSS (version 13.0, SPSS, Chicago, USA). One-way ANOVA was used to test the difference among the 8 tissues. Post Hoc Tests (LSD) were used to compare the mean differences between tissues. Forwards stepwise multiple linear regression analysis was used to determine the effect of altitude, body mass, body length, mean annual temperature and mean annual rainfall on zokor Epo mRNA levels in the kidney and liver. Differences were considered to be significant for a $P<0.05$.

\section{Results}

\subsection{Sexual dimorphism}

Eighty-eight adult zokors (58 females and 30 males) were captured in the field. There was sexual dimorphism in body weight $\left(\mathrm{BW}_{\widehat{O}}=362.20 \pm 13.83 \mathrm{~g}\right.$, BW $+=239.90 \pm 8.85 \mathrm{~g}$, $t=6.84, P<0.001)$, body length $\left(\mathrm{BL}_{\hat{O}} \hat{=}=210.20 \pm 2.93 \mathrm{~mm}\right.$, $\mathrm{BL} q=185.30 \pm 2.13 \mathrm{~mm}, t=6.84, P<0.001)$, relative fatness $\left(\mathrm{RF}_{\widehat{O}}=1.71 \pm 0.05 \mathrm{~g} / \mathrm{mm}, \mathrm{RF}+=1.28 \pm 0.03 \mathrm{~g} / \mathrm{mm}, t=\right.$ $7.47, P<0.001)$, tail length $\left(\mathrm{TL}_{0} \hat{0}=48.93 \pm 1.09 \mathrm{~mm}\right.$, TL 9 $=41.07 \pm 0.96 \mathrm{~mm}, t=5.04, P<0.001)$, and hind feet length $\left(\mathrm{HFL}_{\hat{O}}=37.40 \pm 0.39 \mathrm{~mm}, \mathrm{HFL} q=33.90 \pm 0.26\right.$ $\mathrm{mm}, t=7.55, P<0.001)$.

\subsection{Cloning and sequence analysis of the zokor Epo gene}

The core region of the zokor Epo gene was cloned and sequenced. The full-length coding sequence was 579 bp with the ATG start codon located at position 7 and the TGA stop codon at position 578. The sequence was submitted to the GenBank database under accession no. EU183314.

The deduced Epo protein was composed of 192 amino acids with a predicted molecular weight of $18.655 \mathrm{kD}$ and an isoelectric point (pI) of 7.914. The protein contained an apparent signal peptide sequence of 26 amino acids with a signal cleavage site between Gly-26 and Ala-27 (Figure 1). The result of a multiple sequence alignment indicated that the mature zokor Epo shared a high degree of homology with Epo of other organisms: $81 \%$ for humans (NM_000799), 85\% for mice (NM_007942), 85\% for rats (NM_017001), 85\% for root voles, Microtus oeconomus (DQ658370), 95\% for Golan Heights blind mole rats, Spalax golani (AJ715792), 95\% for Mt. Carmel blind mole rats, Spalax carmeli (AJ715793), 95\% for Judean Mountains blind moles rats, Spalax judaei (J715794), and 95\% for Upper Galilee Mountains blind mole rats, Spalax galili (AJ715795) (Figure 2).

Predicted motifs of zokor Epo included three $\mathrm{N}$-glycosylation sites, two casein kinase II phosphorylation sites, two protein kinase $\mathrm{C}$ phosphorylation sites, one erythropoietin/thrombopoeitin signature site and one cell attachment sequence site. Two single nucleotide polymorphisms sites (SNPs, defined as a single base-pair difference between two copies of a DNA sequence from two individuals) were identified at $36 \mathrm{M}-\mathrm{A} / \mathrm{G}$ and $168 \mathrm{M}-\mathrm{C} / \mathrm{A}$. 


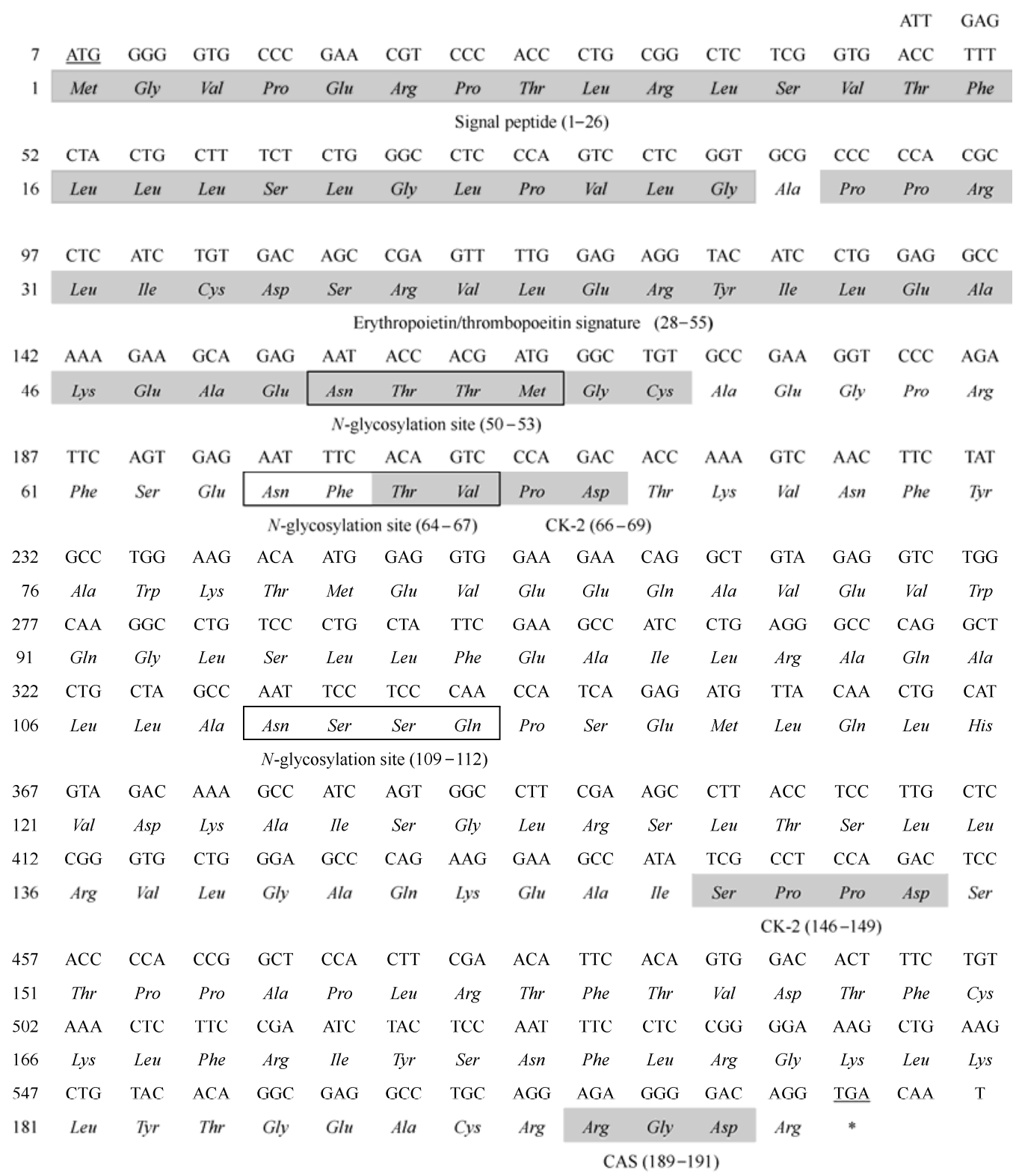

Figure 1 Plateau zokor Epo mRNA and deduced amino acid sequence. The predicted motifs and signal peptide sequence are shaded with a grey background and are labeled. Boxed amino acid sequences indicate the $N$-glycosylation motif sites. The start codon ATG and the stop codon TGA are underlined. The asterisk in the amino acid sequence indicates the stop codon. The GenBank accession number of the plateau zokor Epo gene is 1021725 . The motif abbreviations are: CK-2, casein kinase II phosphorylation site; CAS, cell attachment sequence; SNP, 36 M-A/G; 168 M-C/A.

\subsection{Epo expression in various tissues}

The relative expression of Epo $\left(2^{-\Delta \Delta C_{\mathrm{T}}}\right)$ in selected tissues of the adult plateau zokor varied significantly $\left(F_{7,88}=51.719\right.$, $P<0.001$, Figure 3). There was a high level of Epo mRNA per gram of tissue in the kidney $(4.53 \pm 1.97)$ and spleen $(3.50 \pm 1.30)$. Brain $(1.00 \pm 0.00)$, lung $(0.57 \pm 0.15)$ and liver $(0.42 \pm 0.15)$ exhibited medium levels, while heart $(0.09 \pm 0.04)$, muscle $(0.06 \pm 0.02)$ and white adipose tissue $(0.05 \pm 0.02)$ showed low levels. The amount of Epo mRNA/g tissue in kidney and spleen was 13-fold and 8-fold higher than in liver, respectively. For each adult individual, whether male or female, the organ coefficient was relatively constant. In selected tissues, the organ coefficient of liver and kidney was much higher than in other tissues. Therefore, considering organ weight, the total amount of Epo mRNA in the liver was half that detected in kidney and 2.3-fold that in spleen. The kidney and liver were the dominant organs of the relative contribution to total body Epo mRNA in the plateau zokor.

\subsection{Comparison of Epo gene expression in plateau zokors from different altitudes}

To reveal the major environmental factors affecting expression of zokor Epo, stepwise multiple regression analysis 


\begin{tabular}{|c|c|c|c|}
\hline Mus musculus & MGVPERPTLL LLLSLLLIPL & GLPVLCAPPR LICDSRVLER YILEAKEAEN & 5( \\
\hline Rattus norvegicus & $\ldots$ & $\ldots \ldots \ldots \ldots$ & 5 \\
\hline Microtus oeconomus & $\ldots \ldots \ldots \ldots \ldots$. & 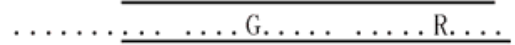 & 5( \\
\hline Spalax judaei & ... . DCLA. P .. VTF. . LS. & $\ldots \ldots G . \ldots \ldots \ldots \ldots \ldots$ & \\
\hline Spalax carmeli & ... DCLA. P .. VTF. . LS. & $\ldots \ldots G . \ldots \ldots \ldots \ldots \ldots$ & \\
\hline Spalax galili & ... DCLA. P . .VTF. . LS. & $\ldots \ldots$ G. $\ldots \ldots \ldots \ldots \ldots \ldots$ & ( \\
\hline Spalax golani & ... DCLA. P . VTF. . LS. & $\ldots \ldots G . \ldots \ldots \ldots \ldots \ldots \ldots$ & \\
\hline Myospalax baileyi & . R . SVTF. . LS. & $\ldots \ldots G . \ldots \ldots \ldots \ldots \ldots$ & \\
\hline Homo sapiens & ...H. C. A.W ......SL. . & $\ldots \ldots$ G............L. . . . & \\
\hline Mus musculus & R LSENITVPDT & KVNFYAWKRM EVEEQAIEVW QGLSLLSEAI & $0 c$ \\
\hline Rattus norvegicus & $\ldots \ldots \ldots \ldots$ & $\ldots \ldots \ldots$ к. $\ldots$ v... $\ldots \ldots \ldots$ & 10( \\
\hline Microtus oeconomus & $\ldots \ldots$ & $\ldots$.......... . . . . & 100 \\
\hline Spalax judaei & FN. F. . & $\ldots \ldots$ T. G. ... . . .... & 100 \\
\hline Spalax carmeli & FN. F. . & $\ldots \ldots \ldots$ T. G...V. . . . . F. & 100 \\
\hline Spalax galili & FN. F. . & $\ldots \ldots$ T. G. $\ldots$ V. . . . . F. & 100 \\
\hline Spalax golani & FN. F. . & $\ldots \ldots \ldots$ T. G. $\ldots$ V... ..... & 10( \\
\hline Myospalax baileyi & F...F.... & $\ldots \ldots \ldots$ T. $\ldots \ldots$ V. $\ldots \ldots$ F. & 100 \\
\hline Homo sapiens & . N..... & $\ldots \ldots \ldots \ldots$.GQ. .V. . . .A.. & 10( \\
\hline Mus musculus & LQAQALLANS SQPPETLQLH & IDKAISGLRS LTSLLRVLGA QKELMI & 15( \\
\hline Rattus norvegicus & $\ldots$...... & $\ldots \ldots \ldots \ldots \ldots \ldots \ldots \ldots$ & 15( \\
\hline Microtus oeconomus & $\ldots$ SGM. ... & $\ldots \ldots \ldots \ldots \ldots \ldots \mathrm{SI}$ & 15( \\
\hline Spalax judaei & ... S. M. ... & $V \ldots \ldots \ldots \ldots \ldots A \ldots A \mathrm{AI}$ & 150 \\
\hline Spalax carmeli & ... S. M. ... & $\mathrm{V} \ldots \ldots \ldots \ldots \mathrm{A} \ldots \ldots \mathrm{AI}$ & 150 \\
\hline Spalax galili & ... S. M. ... & $V \ldots \ldots \ldots \ldots A \ldots \ldots A I$ & 150 \\
\hline Spalax golani & ... S. M. ... & $V \ldots \ldots \ldots \ldots A \ldots \ldots A I$ & 15( \\
\hline Myospalax baileyi & ...S. M. ... & $\mathrm{V} \ldots \ldots \ldots \ldots \ldots \ldots \ldots \mathrm{AI}$ & 150 \\
\hline Homo sapiens & . RG... V. . ... W. P... & V... V.... . . . . . . A & 150 \\
\hline Mus musculus & TPPAPLRTLT VDTFCKLFRV & YANFLRGKLK LYTGEVCRRG DR & 192 \\
\hline Rattus norvegicus & QA..... A........ &. S. $\ldots \ldots \ldots \ldots$ A. $\ldots$ & 19 \\
\hline Microtus oeconomus & $\ldots \ldots \ldots, \mathrm{M} \cdot \mathrm{EN} \ldots \ldots$. &.$S \ldots \ldots \ldots \ldots \ldots A \ldots$ & 19 \\
\hline Spalax judaei &. QVI...RF. .......I &.$S \ldots \ldots \ldots \ldots$ A. $\ldots$ & 19 \\
\hline Spalax carmeli & .QVI...RF. ........I &.$S \ldots \ldots \ldots \ldots A \ldots \ldots$ & 19 \\
\hline Spalax galili &. QVI...RF. ........I &.$S \ldots \ldots \ldots \ldots A \ldots \ldots$ & 19 \\
\hline Spalax golani &. QVI...RF. . . . . . . I &.$S \ldots \ldots \ldots \ldots A \ldots \ldots$ & 19 \\
\hline Myospalax baileyi & $\ldots \ldots \ldots$ F. $\ldots \ldots \ldots$ I &.$S \ldots \ldots \ldots \ldots$ A. $\ldots$ & 19 \\
\hline Homo sapiens & ASA.... I. A...R.... & S. $\ldots \ldots \ldots$ A. . T. $\ldots$ & 19 \\
\hline
\end{tabular}

Figure 2 Multiple alignments of Epo amino acid sequences. Residues identical to Mus musculus Epo are presented as dots (.). The predicted motifs are shown using shadings of different colors (protein kinase C phosphorylation site (PKC), yellow; casein kinase II phosphorylation site (CK2), red; $\mathrm{N}$-glycosylation site, green). Underlined amino acid sequences indicate the motif of the erythropoietin/ thrombopoeitin signature site. Convergent evolution sites between M. baileyi and Spalax sp. are shown using grey shading. The numbers at the right are the total numbers of amino acids.

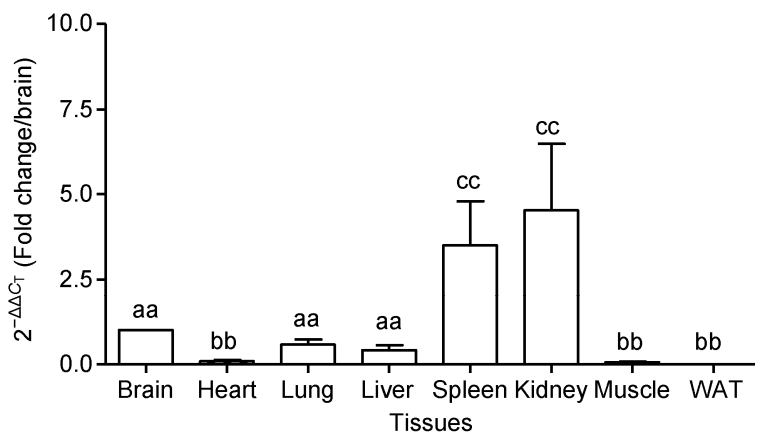

Figure 3 Epo mRNA levels $\left(2^{-\Delta \Delta C_{\mathrm{T}}}\right)$ in different tissues of the plateau zokor. Data are presented as mean $\pm \mathrm{SEM}, n=12$ in each group. Bars with different letters $(\mathrm{aa}, \mathrm{bb}, \mathrm{cc})$ indicate significant differences $(P<0.01)$ with three grades. WAT, white adipose tissue. was used to determine how altitude (Al, in $\mathrm{m}$ ), mean annual temperature $\left(T \mathrm{~m},{ }^{\circ} \mathrm{C}\right)$ and mean annual rainfall $(R \mathrm{n}$, in $\mathrm{mm})$ influenced zokor Epo expression in liver and kidney (Table 1). The results showed that the levels of Epo mRNA in kidney $\left(r=0.8373, F_{1,86}=144.00, P<0.001\right.$; Figure $4($ a) $)$ and liver $\left(r=0.7790, F_{1,86}=144.00, P<0.001\right.$; Figure 4(a)) were significantly increased with altitude. The slope for kidney (0.0055) was 5 times higher than that for the liver (0.0011). Remarkably, the level of Epo mRNA in the kidney of zokors living at the highest altitude $(4268 \mathrm{~m})$ was 12-fold higher than that of zokors at the lowest altitude (2492 m). Mean annual temperature (Figure 4(b)) and mean annual rainfall (Figure 4(c)) were not significantly correlated with Epo expression in liver and kidney (Table 2, Figure 4). 

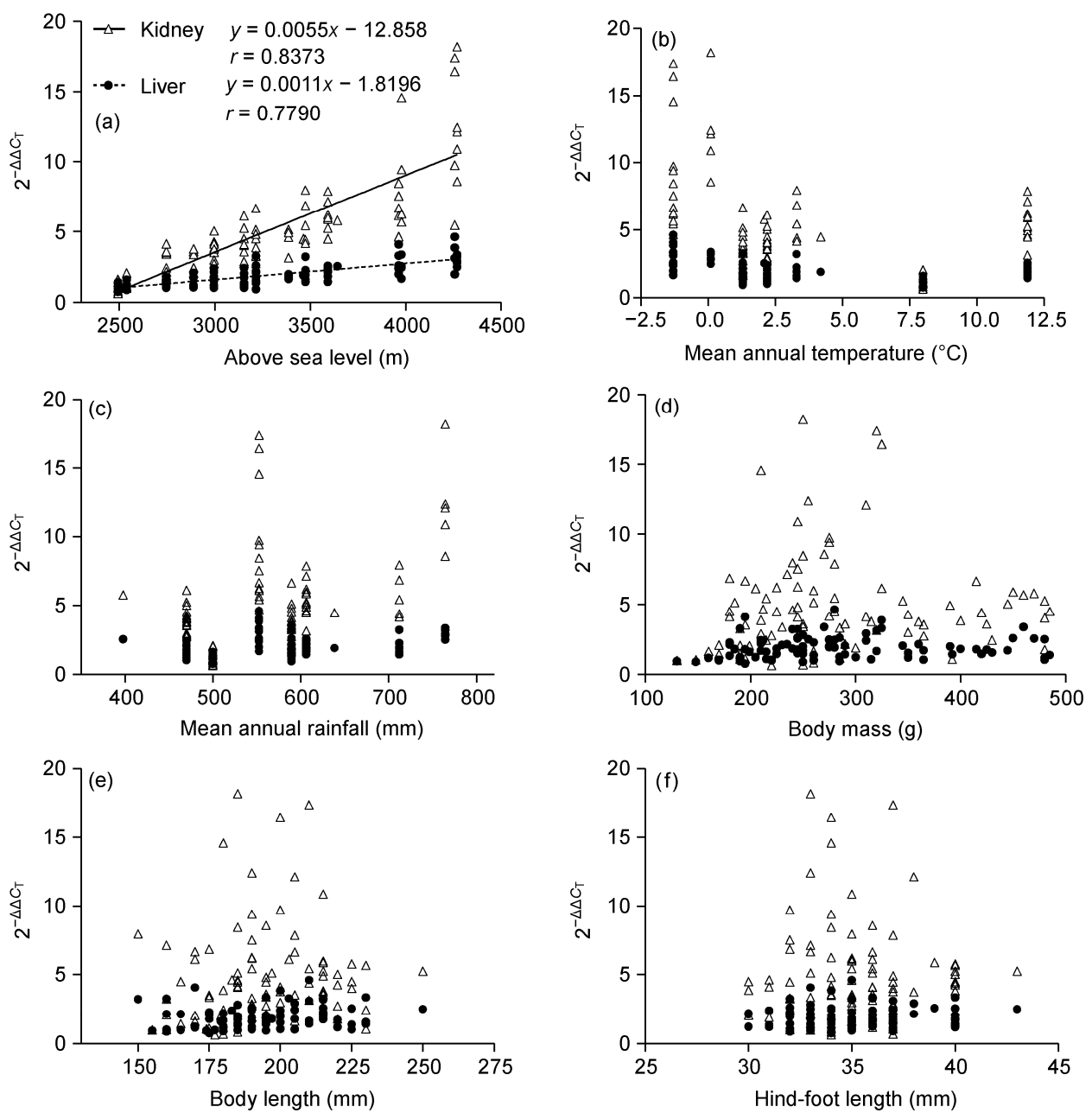

Figure 4 Relative quantification the relationship of Epo mRNA levels in the kidney and liver of the plateau zokor with respect to different altitudes, mean annual temperature, body length, hind-foot length, body mass and mean annual rainfall using the $2^{-\Delta \Delta C_{\mathrm{T}}}$ method.

Furthermore, no correlation was found between Epo expression and body weight (Figure 4(d)), body length (Figure 4(e)), and hind-foot length (Figure 4(f)).

\section{Discussion}

Erythropoietin (Epo) is a glycoprotein hormone essential for normal erythropoiesis. In this study, we cloned the Epo gene of the plateau zokor and compared its expression pattern among 8 tissues and across 16 different altitudes using real-time PCR. The full-length zokor Epo gene is 579 bp that encodes a precursor peptide of 192 amino acids with a signal peptide of 26 residues. The nucleotide and deduced amino acid sequences were highly conserved with those of human, mouse, rat, root vole, and Golan Heights blind mole rat. Of note, zokor Epo is 95\% identical to Spalax Epo. Although zokor and Spalax sp. belong to different taxonomic genera, the predicted secondary and tertiary structure of zokor Epo is highly similar to that of the Spalax genus [29]. The similarity in Epo structure of subterranean rodents may be related to their similar hypoxic living environments. In addition, research on hypoxic stress tolerance of Spalax has found higher levels of Epo expression in Spalax kidney under sustainable hypoxia [25]. Similarly, we found that there was a tendency for the levels of Epo mRNA to increase in the high-altitude zokor kidney. As altitude increases, the concentration of oxygen in hypoxic-hypercapnic burrows will decrease. This suggests that the shared characteristics of EPO between the plateau zokor and the blind subterranean mole rat (Spalax) may be a result of genetically evolved adaptation to cope with hypoxic stress of the subterranean lifestyle.

Epo is synthesized mainly in fetal liver [14] and this expression is shifted to the kidney shortly after birth [15]. In the adult mammal, the kidney is the major site of Epo production. Extrarenal sites produce smaller amounts of Epo in the adult, including liver, lung, spleen, brain and testis [30]. Our results showed the same conclusion that Epo was mainly produced by the kidney in adult zokors. The amount of Epo mRNA/g tissue in kidney was 13-fold higher than that in liver. In the spleen, we also detected a considerable 
Table 2 Models obtained by stepwise multiple regression analysis on factors that explained the variation of Epo mRNA levels in zokor liver and kidney a)

\begin{tabular}{|c|c|c|c|c|}
\hline Dependent variables & $\beta$ & $\mathrm{B} \pm \mathrm{SE}$ & $t$ & $P$ \\
\hline \multicolumn{5}{|l|}{ Kidney } \\
\hline \multicolumn{5}{|l|}{ Accepted variables } \\
\hline Intercept & & $-12.841 \pm 1.302$ & -9.862 & $<0.001$ \\
\hline Altitude & 0.833 & $0.0055 \pm 0.0001$ & 13.803 & $<0.001$ \\
\hline \multicolumn{5}{|l|}{ Excluded variables } \\
\hline Sex & -0.020 & & -0.323 & 0.748 \\
\hline Body mass & -0.026 & & -0.433 & 0.666 \\
\hline Body length & -0.059 & & -0.957 & 0.342 \\
\hline Hind-foot length & -0.056 & & -0.891 & 0.367 \\
\hline Mean annual temperature & -0.070 & & -1.082 & 0.282 \\
\hline Mean annual rainfall & 0.070 & & 1.034 & 0.304 \\
\hline \multicolumn{5}{|l|}{ Liver } \\
\hline \multicolumn{5}{|l|}{ Accepted variables } \\
\hline Intercept & & $-21.72 \pm 2.04$ & -5.453 & $<0.001$ \\
\hline Altitude & 0.776 & $0.0011 \pm 0.0001$ & 11.285 & $<0.001$ \\
\hline \multicolumn{5}{|l|}{ Excluded variables } \\
\hline Sex & 0.016 & & 0.234 & 0.815 \\
\hline Body mass & 0.032 & & 0.461 & 0.645 \\
\hline Body length & -0.006 & & -0.079 & 0.937 \\
\hline Hind-foot length & -0.005 & & -0.071 & 0.956 \\
\hline Mean annual temperature & -0.084 & & -1.146 & 0.255 \\
\hline Mean annual rainfall & -0.026 & & -0.337 & 0.737 \\
\hline
\end{tabular}

a) Independent variables were: altitude ( $\mathrm{Al}$, in $\mathrm{m})$, sex, body mass $(\mathrm{g})$, body length $(\mathrm{mm})$, mean annual temperature $\left({ }^{\circ} \mathrm{C}\right)$ and mean annual rainfall $(\mathrm{mm})$. Standardized (B) and nonstandardized $(\beta)$ regression coefficients and their standard errors are shown. The table provides results from $t$-tests $(t)$ and associated $P$ values.

amount of Epo mRNA/g tissue with a level 8-fold higher than that in liver, which was different from previous reports of Epo tissue-specific expression in human, mouse, rat and other species. Furthermore, there were medium levels in brain, lung and liver and low levels in heart, muscle and white adipose tissue. In conclusion, the expression of Epo in the adult plateau zokor has tissue specificity. As far as the relative contribution of the different organs to total body EPO production, the organ coefficients in liver and kidney were much higher than in other selected tissues. In our results, the total amount of Epo mRNA in the liver was half that detected in kidney and 2.3-fold that in spleen. Therefore, the kidney and liver were the dominant organs for Epo expression in the adult plateau zokor.

All organisms encounter changes in their environment. Responding to environmental challenges and stresses can result, at least over evolutionary time, in the establishment of new and unique metabolic adaptations [1,31]. Different genotypes will show different adaptations to the ever changing environment in which organisms live. This genome-phenome relationship that results from different ecological-genetic patterns demonstrates that this system is a tightly structured one and dependent on abiotic and environmental diversity [29]. If differences in Epo gene sequence and function between zokor and non-zokor species are a result of adaptation to plateau living, we would expect some fine-scale within-species variation in expression. The cold and hypoxic conditions, characteristics of the Qinghai-Tibet Plateau, provide us with a good opportunity to examine some of the drivers of change of Epo expression. We found that zokors living at higher altitudes show relatively higher levels of Epo expression. The relationship between Epo expression in the kidney and altitude was 5 times stronger than that in the liver. The known correlation between altitude and barometric pressure or inspired oxygen pressure is negative $[32,33]$. As altitude increases, air oxygen content decreases and hypoxia develops. Therefore, differences in altitude and hypoxia across our 16 sampling sites were the most important factors affecting Epo expression in this species and had a profound effect on the adaptation of the zokor to plateau living.

Plateau zokors mostly spend their life in sealed burrows. In their hypoxic-hypercapnic burrows, the temperature and humidity is relatively constant, but the concentration of oxygen and carbon dioxide fluctuates with the changing seasons, rainfall, and the ambient temperature [34]. The $\mathrm{O}_{2}$ concentration is probably much lower when the burrows are flooded with rainwater or the earth is frozen in winter. High rainfall will drastically limit gas solubility and permeability [29]. Ambient temperature is related to the freeze-thaw of 
the seasonal permafrost in the Qinghai-Tibet Plateau. When the surface is frozen or thawing, soil ventilation and gas permeability are restricted, resulting in an increase of hypoxic stress [35]. Moreover, zokors will increase oxygen consumption because of the extreme cold [36]. Consequently, plateau zokors are confronted by persistent hypoxia during winter. Although rainwater and frozen earth limit gas permeability and low temperature increases oxygen consumption, our data showed that neither mean annual temperature nor mean annual rainfall were related to the level of Epo. These two factors may have an indirect influence, rather than by directly producing an effect on the level of gene expression. In addition, there was sexual dimorphism in body weight, body length, relative fatness, tail length and hind feet length. Age and sex are positively associated with body mass and body length in zokors [37], but we did not find correlations between levels of Epo expression and body mass, body length, age or sex.

\section{Conclusions}

In conclusion, zokor Epo has a high degree of homology to Spalax Epo. Altitude is a major factor that affects Epo expression in the plateau zokor. These results suggest that Epo may play an essential role in the plateau zokor in ecological adaptation to the harsh plateau environment.

This work was supported by Key Innovation Research Program, Chinese Academy of Sciences (KSCX2-EW-N-05), the National Basic Research Program of China (2012CB722506), and the Key Projects in the National Science \& Technology Pillar Program (2009BAI83B01).

1 Storey K B. Stress-induced gene expression in freeze tolerant and anoxia tolerant vertebrates. In: Storey K B, ed. Environmental Stress and Gene Regulation. Oxford: BIOS Scientific Publishers, 1999. 1-23

2 Su J, Wang Z. Studies on the population energetics of plateau zokor: I. Average daily metabolic rate and burrowing metabolic rate. Acta Theriol Sin, 1992, 12: 200-206

3 Yang J, Zhao X Q, Guo S C, et al. Leptin cDNA cloning and its mRNA expression in plateau pikas (Ochotona curzoniae) from different altitudes on Qinghai-Tibet Plateau. Biochem Biophys Res Commun, 2006, 345: 1405-1413

4 Zhang Y M, Liu J. Effects of plateau zokors (Myospalax fontanierii) on plant community and soil in an alpine meadow. J Mammal, 2003, 84: 644-651

5 Zhang Y M. The biology and ecology of plateau zokors (Eospalax fontanierii). In: Begall S, Burda H, Schleich C E, eds. Subterranean Rodents: News from Underground. Heidelberg: Springer-Verlag, 2007. 237-249

6 Zhang Y M, Zhang Z B, Liu J K. Burrowing rodents as ecosystem engineers: The ecology and management of plateau zokors Myospalax fontanierii in alpine meadow ecosystems on the Tibetan Plateau. Mammal Rev, 2003, 33: 284-294

7 Zhang Y M. Influence of plateau zokors (Eospalax fontanierii) on alpine meadows. In: Begall S, Burda H, Schleich C E, eds. Subterranean Rodents: News from Underground. Heidelberg: Springer-Verlag, 2007. 301-308
8 Qi X Z, Wang X J, Zhu S H, et al. Hypoxic adaptation of the hearts of plateau zokor (Myospalax baileyi) and plateau pika (Ochotona curzoniae). Acta Physiol Sin, 2008, 60: 348-354

9 Wei D B, Zhang J M, Wei L, et al. Seasonal changes in blood physiological parameters related to adaptation to hypoxia-hypercapania in plateau zokors. Acta Zool Sin, 2006, 52: 871-877

10 Wang X J, Wei D B, Wei L, et al. Physiological character of erythrocyte adapting to hypoxia in plateau zokor and plateau pika. Sichuan J Zool, 2008, 27: 1100-1104

11 Wei D, Wei L. The mensuration results of the number of red cell, the density of hemoglobin and the contents of myoglobin in Plateau Zokor. J Qinghai Univ, 2001, 19: 10-13

12 Wen D, Boissel J P R, Tracy T E, et al. Erythropoietin structurefunction-relationships: High-degree of sequence homology among mammals. Blood, 1993, 82: 1507-1516

13 Sytkowski A J. Denaturation and renaturation of human erythropoietin. Biochem Biophys Res Commun, 1980, 96: 143-149

14 Jacobson L O, Goldwasser E, Fried W, et al. Role of the kidney in erythropoiesis. Nature, 1957, 179: 633-634

15 Zanjani E D, Poster J, Burlington $\mathrm{H}$, et al. Liver as primary site of erythropoietin formation in fetus. J Lab Clin Med, 1977, 89: 640-644

16 Schooley J C, Mahlmann L J. Evidence for the De Novo synthesis of erythropoietin in hypoxic rats. Blood, 1972, 40: 662-670

17 Erslev A J. In vitro production of erythropoietin by kidneys perfused with a serum-free solution. Blood, 1974, 44: 77-85

18 Goldberg M A, Dunning S P, Bunn H F. Regulation of the erythropoietin gene: Evidence that the oxygen sensor is a heme protein. Science, 1988, 242: 1412-1415

19 Kurtz A, Eckardt K E, Tannahill L, et al. Regulation of erythropoietin production. Contrib Nephrol, 1988, 66: 1-16

20 Ebert B L, Bunn H F. Regulation of the erythropoietin gene. Blood, 1999, 94: 1864-1877

21 Rosse W F, Waldmann T A. Metabolism of erythropoietin in patients with anemia due to deficient erythropoiesis. J Clin Invest, 1964, 43: 1348-1349

22 Fukuda M N, Sasaki H, Lopez L, et al. Survival of recombinant erythropoietin in the circulation: The role of carbohydrates. Blood, 1989, 73: 84-89

23 Jelkmann W, Wiedemann G. Serum erythropoietin level: Relationships to blood hemoglobin concentration and erythrocytic activity of the bone marrow. Klin Wochenschr, 1990, 68: 403-407

24 Shams I, Nevo E, Avivi A. Ontogenetic expression of erythropoietin and hypoxia-inducible factor-1 alpha genes in subterranean blind mole rats. FASEB J, 2005, 19: 307-309

25 Shams I, Avivi A, Nevo E. Hypoxic stress tolerance of the blind subterranean mole rat: Expression of erythropoietin and hypoxia-inducible factor 1 alpha. Proc Natl Acad Sci USA, 2004, 101: 9698-9703

26 Vilalta A, Wu D, Margalith M, et al. Rabbit EPO gene and cDNA: Expression of rabbit EPO after intramuscular injection of pDNA. Biochem Biophys Res Commun, 2001, 284: 823-827

27 David R B, Blom A K, Sjaastad O V, et al. The porcine erythropoietin gene: cDNA sequence, genomic sequence and expression analyses in piglets. Domest Anim Endocrinol, 2001, 20: 137-147

28 Livak K J, Schmittgen T D. Analysis of relative gene expression data using real-time quantitative PCR and the 2(-Delta Delta CT) method. Methods, 2001, 25: 402-408

29 Nevo E. Evolution of genome-phenome diversity under environmental stress. Proc Natl Acad Sci USA, 2001, 98: 6233-6240

30 Tan C C, Eckardt K U, Ratcliffe P J. Organ distribution of erythropoietin messenger RNA in normal and uremic rats. Kidney Int, 1991, 40: 69-76

31 Wilhelm V, Villegas J, Miquel A, et al. The complete sequence of the mitochondrial genome of the chinook salmon, Oncorhynchus 
tshawytscha. Biol Res, 2003, 36: 223-231

32 Pugh L G. Resting ventilation and alveolar air on Mount Everest: With remarks on the relation of barometric pressure to altitude in mountains. J Physiol, 1957, 135: 590-610

33 Peacock A J. ABC of oxygen: Oxygen at high altitude. Brit Med J, 1998, 317: 1063-1066

34 Qi X Z, Wang X J, Zhu S H, et al. Hypoxic adaptation of the hearts of plateau zokor (Myospalax baileyi) and plateau pika (Ochotona curzoniae). Acta Physiol Sin, 2008, 60: 348-354
35 Grubb B, Folk G E. Effect of cold-acclimation on norepinephrine stimulated oxygen-consumption in muscle. J Comp Physiol, 1976, 110: $217-226$

36 Wei D B, Wei L, Zhang J M, et al. Blood-gas properties of plateau zokor (Myospalax baileyi). Comp Biochem Physiol A Mol Integr Physiol, 2006, 145: 372-375

37 Zhang Y M. Effect of removal on age structure and reproduction of plateau zokor population in alpine meadow. Acta Theriol Sin, 1999, 19: 204-211

Open Access This article is distributed under the terms of the Creative Commons Attribution License which permits any use, distribution, and reproduction in any medium, provided the original author(s) and source are credited. 